\title{
TRANSTORNO DO ESPECTRO AUTISTA: DETECÇÃO PRECOCE PELO ENFERMEIRO NA ESTRATÉGIA SAÚDE DA FAMÍLIA
}

\section{AUTISTIC SPECTRUM DISORDER: EARLY DETECTION BY FAMILY HEALTH STRATEGY NURSES}

\section{TRASTORNO DEL ESPECTRO AUTISTA: DETECCIÓN PRECOZ DEL ENFERMERO EN LA ESTRATEGIA SALUD DE LA FAMILIA}

\author{
Yanna Cristina Moraes Lira Nascimento ${ }^{1}$ \\ Cintia Soares Cruz de Castro ${ }^{2}$ \\ José Leandro Ramos de Lima ${ }^{3}$ \\ Maria Cicera dos Santos de Albuquerque ${ }^{4}$ \\ Daniele Gonçalves Bezerra ${ }^{5}$
}

Como citar este artigo: Nascimento YCML, Castro CSC, Lima JLR, Albuquerque MCS, Bezerra DG. Transtorno do espectro autista: detecção precoce pelo enfermeiro na Estratégia Saúde da Família. Rev baiana enferm. 2018;32:e25425.

Objetivo: identificar a atuação do enfermeiro da Estratégia Saúde da Família na detecção precoce do Transtorno do Espectro Autista em crianças. Método: pesquisa descritiva, exploratória, qualitativa realizada numa capital do Nordeste, Brasil. Participaram 10 enfermeiros efetivos, concursados e em exercício na Estratégia Saúde da Família. A coleta de dados ocorreu em 2014 por meio de entrevista individual, observação direta e diário de campo. Material tratado pela análise temática, interpretado pelo referencial das Diretrizes de Atenção à Reabilitação da Pessoa com Transtorno do Espectro Autista. Resultados: foram áreas temáticas: percepção, estratégias e intervenções do enfermeiro sobre sinais e sintomas; dificuldades relatadas à detecção precoce; construção do conhecimento sobre a temática; e sentimentos dos profissionais ao acompanharem crianças com Transtorno do Espectro Autista. Conclusão: enfermeiros da Estratégia Saúde da Família apresentaram deficiências na detecção precoce do Transtorno do Espectro Autista em crianças.

Descritores: Transtorno autístico. Cuidado da criança. Estratégia Saúde da Família. Intervenção precoce (Educação).

Objective: to identify the role of Family Health Strategy nurses in the early detection of Autistic Spectrum Disorder in children. Method: descriptive, exploratory, qualitative research carried out in a capital city in the Northeast

\footnotetext{
Enfermeira. Mestra em Enfermagem. Especialista em Saúde Mental. Especialista em Ativação de Processos de Mudança na Formação Superior de Profissionais de Saúde. Docente dos cursos de Enfermagem e Medicina da Universidade Federal de Alagoas. Coordenadora de projetos de extensão em saúde mental e atenção básica em cooperação com a Secretaria Municipal de Saúde da Prefeitura de Maceió. Articuladora do Fórum de Saúde Mental da Universidade Federal de Alagoas Nise da Silveira. Membro do Grupo de Pesquisa em Saúde Mental, Álcool e outras Drogas Austregésilo Carrano Bueno. Maceió, Alagoas, Brasil. yanna.lira@esenfar.ufal.br Enfermeira. Bolsista de Iniciação Científica do Conselho Nacional de Desenvolvimento Científico e Tecnológico durante a graduação. Maceió, Alagoas, Brasil.

3 Graduando do curso de Enfermagem na Universidade Federal de Alagoas. Participante do Grupo de Pesquisa Saúde Mental, Álcool e outras Drogas Austregésilo Carrano Bueno, na Universidade Federal de Alagoas. Bolsista de Iniciação Científica do Conselho Nacional de Desenvolvimento Científico e Tecnológico. Maceió, Alagoas, Brasil.

Enfermeira e Psicóloga. Doutora em Enfermagem Fundamental. Mestra em Educação. Docente da graduação e do Programa de Pós-graduação em Enfermagem da Escola de Enfermagem e Farmácia da Universidade Federal de Alagoas. Coordenadora do Laboratório de Saúde Mental, Acolhimento e Relacionamento Interpessoal. Líder do Grupo de Pesquisa Saúde Mental, Álcool e outras Drogas Austregésilo Carrano Bueno. Maceió, Alagoas, Brasil.

Bióloga. Doutora em Biologia Humana e Experimental. Mestra em Morfologia. Docente da Universidade Federal de Alagoas e da Faculdade Estácio de Alagoas. Maceió, Alagoas, Brasil.
} 
region of Brazil. The participants were 10 nurses who took a test to have a permanent job and work in the Family Health Strategy. Data collection took place in 2014 through individual interview, direct observation, and field diary. Thematic analysis was used, with data interpreted by the framework of the Guidelines for Rebabilitation Care of Autistic Spectrum Disorder Patients. Results: the thematic areas were: perception, strategies and interventions of nurses on symptoms and signs; difficulties related to early detection; construction of knowledge on the subject; and professionals' feelings when accompanying children with the Autistic Spectrum Disorder. Conclusion: the Family Health Strategy nurses had deficiencies in the early detection of the Autistic Spectrum Disorder in children.

Descriptors: Autistic disorder. Child care. Family Health Strategy. Early intervention (Education).

Objetivo: identificar la actuación del enfermero de Estrategia Salud de la Familia en la detección precoz del Trastorno del Espectro Autista en niños. Método: investigación descriptiva, exploratoria, cualitativa, realizada en capital del Noreste brasileño. Participaron 10 enfermeros efectivos, concursados y en ejercicio en la Estrategia Salud de la Familia. Datos recolectados en 2014 mediante entrevista individual, observación directa y registro de servicio. Material tratado por análisis temático, interpretado por referencial de Directrices de Atención a la Rehabilitación de la Persona con Trastorno del Espectro Autista. Resultados: las áreas temáticas fueron: percepción, estrategias e intervenciones del enfermero ante señales y sintomas; dificultades informadas en la detección precoz; construcción de conocimiento sobre la temática; y sentimientos de los profesionales al trabajar con niños con Trastorno del Espectro Autista. Conclusión: los enfermeros de la Estrategia Salud de la Familia muestran deficiencias para detectar precozmente el Trastorno del Espectro Autista en niños.

Descriptores: Trastorno autístico. Cuidado del niño. Estrategia de Salud Familiar. Intervención precoz (Educación).

\section{Introdução}

O Transtorno do Espectro Autista (TEA), que afeta áreas do neurodesenvolvimento responsáveis pela interação social, comunicação e comportamento, necessita de intervenções específicas e precoces para potencializar o desenvolvimento infantil, diminuir a possibilidade de cronificação e ampliar propostas terapêuticas ${ }^{(1-2)}$. Estudos estimam que o índice de prevalência do TEA seja de 62/10.000 com incidência quatro vezes maior entre meninos ${ }^{(1)}$. No Brasil ainda não há dados estatísticos oficiais sobre a prevalência desse transtorno, porém estima-se que entre 10\% a $20 \%$ das crianças e adolescentes sofram transtornos mentais. Considera-se que até 4\% dessa população necessita de tratamentos intensivos ${ }^{(3)}$.

Os sintomas do TEA aparecem antes dos três anos de idade e manifestam-se das mais variadas formas, por meio de alterações comportamentais, como medo e confusão mental, baixa tolerância à mudança, dificuldades em compreender regras sociais, desatenção, impulsividade, fuga, comportamentos auto e heteroagressivos. Crianças com autismo revelam respostas próprias a estímulos sensoriais, apresentam resistência a dor, hipersensibilidade ao toque, reações excessivas a odores e demonstram encantamento a estímulos visuais específicos. Além disto, podem apresentar baixa habilidade interpessoal no contato com outras crianças e, inclusive, com pessoas da própria famíliaa ${ }^{(4-5)}$.

Os membros do núcleo familiar têm a maior probabilidade de perceberem precocemente as primeiras alterações ou manifestações do autismo em seu filho. Esta possibilidade concretizada, bem como a participação desses nas intervenções terapêuticas, coloca a criança em situação favorável à experiência de uma vida mais próxima da autonomia ${ }^{(1)}$. Para contribuir com tais familiares e com as equipes multiprofissionais para o cuidado à saúde da criança com TEA no âmbito do Sistema Único de Saúde (SUS), o Ministério da Saúde lançou, em 2014, diretrizes para diagnóstico precoce e tratamento, que contemplam o projeto terapêutico singular na perspectiva da habilitação e reabilitação, apoio e acolhimento à família, fluxograma de acompanhamento e atendimento na rede do $\operatorname{SUS}^{(6)}$.

A organização da rede de saúde no território, com seus equipamentos públicos e complementares no nível da atenção básica, deve 
preparar e fortalecer as unidades básicas com suas equipes de saúde da família para atenção integral, individual e coletiva à criança e ao adolescente $^{(7)}$, principalmente nos casos de crianças com TEA e suas famílias. A atuação integrada da atenção básica com diversos serviços reforça a necessidade de atividades voltadas para a promoção da saúde, a prevenção de agravos, além da recuperação e reabilitação da saúde na perspectiva da qualidade de vida. Para isso, é também necessário considerar a efetivação do matriciamento dos serviços de saúde ${ }^{(8)}$, fortalecendo, assim, a rede de atenção psicossocial por meio das articulações com a Estratégia de Saúde da Família (ESF).

Na ESF é possível trabalhar na perspectiva da promoção da saúde e redução dos agravos, acompanhando o crescimento e o desenvolvimento infantil durante as ações de puericultura. O enfermeiro, como membro da equipe multiprofissional, é um dos responsáveis por esse acompanhamento e deve estar preparado para avaliar o desenvolvimento infantil, a fim de detectar precocemente qualquer anormalidade e tomar as medidas resolutivas para a melhoria da qualidade de vida ${ }^{(9)}$, principalmente da criança com TEA e de sua família.

Estudos realizados no interior paulista revelaram que $15 \%$ dos profissionais da atenção básica já entraram em contato com crianças com TEA e suas famílias e que 43\% deles sabiam reconhecer a tríade comportamental que envolve o transtorno. Entretanto, somente 10\% desses profissionais reconheciam os sinais relacionados às manifestações no primeiro ano de vida e, embora 99\% deles reconhecessem a necessidade de tratamento para essas crianças, as terapias utilizadas não eram claramente identificadas ${ }^{(10)}$.

Assim, como a ESF tem no escopo de suas atividades a realização de ações voltadas ao acompanhamento do crescimento e do desenvolvimento infantil, o enfermeiro necessita perceber qualquer alteração de comportamento sugestiva do TEA no atendimento em puericultura. Desse modo, adotou-se como questão norteadora da pesquisa: Como o enfermeiro da ESF atua na detecção precoce do TEA em crianças?
Delineou-se como objetivo, identificar a atuação do enfermeiro da ESF na detecção precoce do TEA em crianças.

\section{Método}

Pesquisa descritiva exploratória de abordagem qualitativa realizada na cidade de Maceió, capital do estado de Alagoas, Brasil, onde enfermeiros foram sujeitos. Identificadas as Unidades Básicas de Saúde (UBS) que possuíam ESF, sortearam-se, de forma aleatória, quais seriam abordadas. Em seguida procedeu-se contato telefônico com os enfermeiros dessas Unidades para agendamento das entrevistas.

Participaram 10 enfermeiros efetivos, com vínculo permanente por concurso público municipal, que exerciam suas atividades na ESF. Foram excluídos enfermeiros afastados do serviço ou de férias no momento do contato. O número de entrevistados seguiu o critério de saturação dos dados, compreendido como o momento em que os dados começam a se repetir em um determinado número de entrevistas ${ }^{(11)}$.

Os dados foram coletados em janeiro e fevereiro de 2014, por meio da triangulação de coleta de dados com a utilização da entrevista individual em profundidade, guiada por um roteiro semiestruturado composto por questões referentes à caracterização dos participantes e à visão que possuíam sobre a criança com TEA e sua família.

Também foram métodos de coleta de dados, a observação direta da atuação do enfermeiro junto à criança durante a consulta de enfermagem na puericultura, em que os estudantes acompanharam atentamente a consulta, descrevendo em relatórios o observado, na tentativa de perceber se sinais alterados do desenvolvimento infantil que sugestionam autismo eram investigados pelo enfermeiro. E ainda as anotações registradas no diário de campo de forma sistematizada, também guiada por um roteiro em que foram pontuados: assunto abordado; data, horário, local e cenário da entrevista; descrição do comportamento da participante envolvida na pesquisa; descrição das atividades observadas no serviço, em que a participante realizava seu 
trabalho; e comentário do pesquisador. A coleta foi realizada por dois graduandos de enfermagem, sendo um deles bolsista do Programa Institucional de Bolsas de Iniciação Científica (PIBIC) vinculado ao Conselho Nacional de Desenvolvimento Científico e Tecnológico (CNPq) e o outro, um colaborador.

O material produzido foi tratado pela análise temática $^{(11-12)}$. Para a operacionalização da análise, três etapas sucessivas foram necessárias: a pré-análise, com o preparo do material, a transcrição das entrevistas gravadas e a leitura flutuante; a exploração do material, com a codificação sucedida da transformação dos dados brutos após recortados, agregados e enumerados; e a classificatória, com a redação do texto. Utilizou-se para análise o referencial das Diretrizes do Ministério da Saúde de Atenção à Reabilitação da Pessoa com TEA.

Este estudo considerou e aplicou as diretrizes e normas regulamentadoras de pesquisas envolvendo seres humanos que constam na Resolução n. 466, de 12 de dezembro de 2012, e obteve aprovação do Comitê de Ética em Pesquisa da Faculdade Estácio de Alagoas, protocolo número 505.852, em 31 de dezembro de 2013. Esses procedimentos garantiram todos os direitos dos participantes após a assinatura do Termo de Consentimento Livre Esclarecido (TCLE).

\section{Resultados}

Os enfermeiros participantes desta pesquisa possuíam de 9 a 18 anos de formação, trabalhavam de 1 a 16 anos na ESF, e 50\% deles relataram contato com o TEA e identificaram seus sinais durante a avaliação de crescimento e desenvolvimento das crianças que acompanhavam. Emergiram, nos discursos dos entrevistados, conteúdos que foram categorizados em quatro áreas temáticas descritas a seguir: Percepção, estratégias e intervenções do enfermeiro sobre sinais e sintomas da criança com TEA, Dificuldades relatadas quanto à detecção precoce do TEA, Construção do conhecimento sobre TEA e Sentimentos dos profissionais ao acompanharem crianças com TEA.

\section{Percepção, estratégias e intervenções do enfermeiro sobre sinais e sintomas da criança com TEA}

Nas narrativas dos participantes, surgiu a percepção de que crianças com TEA apresentavam dificuldades de interação com outras pessoas e com o meio em que estavam inseridas: São vários traços que a pessoa apresenta. É possível des-
confiar daquela criança que fica isolada, que não tem
contato com ninguém, às vezes nem com a mãe [...] (E9).

Os enfermeiros também perceberam outros sinais que possibilitavam fundamentar o diagnóstico de TEA, tais como: movimentos repetitivos, comportamentos estranhos e agressivos, isolamento, brincar de forma diferente, dificuldade em compartilhar brinquedos e dificuldades no sono e na amamentação.

\footnotetext{
São crianças que, na primeira infância, têm alguma dificuldade de socialização e que apresentam repetição de movimentos corporais [...] (E5).

Crianças que brincam sozinhas, não dividem coisas com outras crianças. (E6).

Eu acredito que uma criança menor de seis meses que tenha autismo, tenha dificuldade de coordenar sono e aleitamento [...] (E1).
}

Essas percepções foram ratificadas na observação direta da consulta de enfermagem. Nesta, o profissional acompanha o peso, a altura, a amamentação, a alimentação, a presença de comportamentos inesperados, bem como avaliam se as crianças sentam sem apoio, se sustentam a cabeça no tempo esperado, se observam pessoas ao seu redor, se fazem contato visual, se balbuciam alguma coisa, e se transferem objetos de uma mão para a outra.

Os enfermeiros também divergiram em sua percepção sobre a capacidade cognitiva da criança com TEA. Enquanto afirmou-se que essas crianças apresentavam dificuldades pedagógicas e neurológicas impeditivas à aprendizagem, também houve relato da possibilidade de apresentarem bom desempenho na vida escolar, quando estimuladas.

Eu tenbo uma filha de cinco anos que estuda numa escola que tem crianças especiais. Tem uma professora só para essas crianças, porque elas têm mudança de comportamento: uma hora elas ficam agressivas, outra elas 
conseguem socializar-se. Não conseguem seguir a questão pedagógica; é um pouquinho aquém. (E5).

A minha filha estuda em um colégio que um aluno era autista, e ele tinha um grau bem avançado e boje está fazendo faculdade [...] (E7).

Assim como o desenvolvimento escolar é um importante estímulo para o bom desempenho na vida em sociedade, a identificação precoce dos sinais e sintomas do TEA também é fundamental para o desenvolvimento de habilidades. Esse diagnóstico precoce, porém, segundo os relatos, é de difícil obtenção, sendo necessário aprofundar a observação de forma mais especializada, com profissionais de referência.

Não é tão rápido perceber que uma criança é autista, mas quanto mais cedo descobrir, mais cedo intervir, melhoras vai ter [...] (E7).

É uma criança que requer cuidados mais diretos, com mais detalhes, e com pessoas especializadas [...] (E10).

Foi visível aos entrevistados que questões sociais e familiares estão relacionadas com o contexto de vida dessas crianças. Situações de alimentação precária e violência doméstica interferem no desenvolvimento físico, neurológico e psicológico da família.

Questões de miséria social envolvem a família, e descobrimos que o irmão da criança que acompanhávamos tinha autismo. Essa criança tinha desnutrição violenta, era agitada, batia a cabeça na parede e não falava [...] (E1).

Desse modo, verificou-se que os enfermeiros possuíam a percepção da criança com TEA como aquelas que possuíam características e necessidades diferenciadas das demais, mas era possível investir precocemente em seu desenvolvimento, a fim de inseri-las na sociedade, sendo necessárias intervenções.

No acompanhamento do desenvolvimento infantil, o enfermeiro tem a oportunidade de identificar alterações disfuncionais. Portanto, revelou-se como estratégia, considerar parâmetros para avaliar a ausência de sinais esperados para a idade:

A gente segue aquilo que conbece, como o desenvolvimento da criança de zero a dois anos que a gente mais acompanha. Crianças de seis meses já sentam com algum apoio; crianças de sete, nove meses já começam a engatinhar. A gente testa também o reflexo, usando um parâmetro. Quando estão ausentes, sugere que alguma coisa está acontecendo. (E5).

Além da observação durante a consulta dos sinais disfuncionais presentes na criança, há relatos sobre a necessidade de ouvir os discursos da mãe como estratégia.

Na anamnese, conversando com a mãe, ela diz como a criança está se comportando e de acordo com o comportamento estabelecido para a idade, é que nós avaliamos o desenvolvimento dessa criança... se conbece o próprio nome, se está falando na idade certa, se consegue formar frases, se tem contato com o meio [...] (E8).

Quanto aos procedimentos adotados para suspeita de TEA, alguns afirmaram solicitar avaliação de outros profissionais reconhecendo a necessidade de ampliar o cuidado à família.

Se ela chega e não foi diagnosticada, nós a encaminhamos à consulta médica [...] (E8).

É uma criança que requer cuidado, não só de médicos, mas de uma equipe multiprofissional. Principalmente psicólogos. Acho que a família toda precisa serpreparada para acompanhar a criança pelo resto da vida [...] (E6).

Como método de intervenção, foi mencionada a procura de dispositivos de assistência às pessoas com TEA, serviços especializados e de referência, como o Centro de Atenção Psicossocial Infanto-juvenil (CAPSi).

Acionaria algum setor de psicologia, um CAPSi [...] (E10).

Mas nem sempre o acesso a esses serviços ou até mesmo o conhecimento sobre eles estão claros para os profissionais. Ausência de informações interfere na segurança e propriedade das ações, dificultando a realização de intervenções dirigidas a essas crianças.

\section{Dificuldades relatadas quanto à detecção precoce do TEA}

Entre as dificuldades em detectar sinais e sintomas do TEA, estão a falta de capacitação e divulgação de materiais específicos que incentivem o uso de instrumentos facilitadores à detecção precoce do autismo. A ideia de que a identificação de sinais e sintomas do TEA não é responsabilidade do enfermeiro, também é outra barreira para detecção precoce e intervenção por esse profissional. 
Se nós tivéssemos capacitação para reconhecer e tivéssemos acesso a informações. (E9).

Não conbeço nenbum instrumento, nenbum impresso, nada que me remeta a perceber uma criança autista [...] (E7).

Eu não sei atender criança com autismo. E nem é uma coisa que cabe a mim. Eu não seria a pessoa adequada para detectar [...] (E6).

Aliado a essas expressões, observou-se, nos diários de campo, a inquietação do enfermeiro sobre a falta de informação e a necessidade de espaços para a formação, quando questionado sobre a temática.

Outra dificuldade apontada foi a ausência de protocolos com a descrição da rede de atenção psicossocial, que oriente quais os serviços de referência e entraves encontrados na busca pelo diagnóstico precoce, quando necessitam do apoio de outros profissionais da rede. Não está escrito o que tem que fazer, porque não existe
protocolo para isto [...] (E7).

Se tivéssemos um organograma para onde encaminhar a criança, seria interessante. (E6).

Está muito difícil de fechar o diagnóstico. As mães têm dificuldades em marcar um psiquiatra. É muito demorado marcar um psiquiatra infantil [...] (E9).

Ademais, muitas vezes, os cuidadores não relatam o comportamento da criança em casa, dificultando a percepção de alterações no desenvolvimento infantil.

A gente considera muito o que a mãe fala. Se a mãe não passasse essa informação da criança pra mim seria um problema. Porque a gente tem umas mães que são dispersas e não observam muito a criança [...] (E3).

A família passa a ter um papel fundamental em todo o processo desde a identificação até a adesão ao tratamento, no entanto há situações em que a família pode tornar-se fator de risco para o desempenho de uma criança com TEA, principalmente quando, por influência de estigmas sociais, a família cria barreiras que impedem a reabilitação da criança. Essas barreiras incluem a negação dos sintomas, o não comparecimento da criança na consulta de puericultura, a própria cultura de buscar o posto de saúde apenas com o surgimento de uma doença, até crenças religiosas, desligamento desse núcleo familiar da ESF, assim como um ambiente familiar desfavorável e conturbado relatado a seguir:

\begin{abstract}
Surgiu uma mãe de uma autista, mas na época ela não aceitava. Ela resistiu muito e depois não apareceu mais. A familia precisava de tratamento. Eles são evangélicos, já aumentava ainda mais a resistência de entender que a filha poderia ser autista [...] (E7).

A minha dificuldade seria das mães frequentarem a puericultura, porque as mães só procuram o atendimento quando a criança está doente [...] Se elas frequentassem, com certeza seria identificado, talvez não drene exatamente o autismo, mas vai drenando alguma coisa fora do normal. Mas a cultura é a criança ir à consulta quando está doente. É preciso desmistificar, fazendo atividades educativas, orientando as mães desde o pré-natal [...] (E8).
\end{abstract}

Dificuldades como a falta do acompanhamento da família e da criança desde o pré-natal aliada à falta de recursos necessários para uma detecção precoce eficaz geram, muitas vezes, insegurança na prática profissional. Assim, para solucionar ou diminuir os entraves, a construção de um conhecimento técnico passa a ser primordial.

\section{Construção do conbecimento sobre TEA}

Nesta condição, a mídia televisiva exerceu influência sobre os entrevistados no tocante à reprodução de conceitos e imagens sobre o TEA. A internet também foi apontada como uma das fontes de informação, um recurso para tirar dúvidas e, assim, auxiliar no dia a dia da profissão:

Tudo que sei é o que a gente vê na TV. Com o autismo sendo abordado na novela, achei interessante acompanhar [...] (E4).

Nunca estudei. A informação que eu tenbo de autismo é através da mídia mesmo. E alguma coisinha que eu li na internet. (E6).

Também foi levantada a importância de terceiros, como colegas de trabalho e familiares como influenciadores da construção do conhecimento sobre o TEA. E dos próprios profissionais, ao compartilharem experiências de forma conjunta.

Uma pessoa da unidade tem um filbo autista, percebi
como fala desta criança [...] (E7).

Sei do autismo porque minha filha trabalha na educacão com crianças autistas [...] (E4).

Nós questionamos, discutimos com os médicos das equipes [...] (E1). 
Aponta-se também a caderneta da criança como outra fonte de conhecimento, nas páginas que trazem informações e orientações sobre o desenvolvimento inadequado:

Minha curiosidade é que, na caderneta da criança, há uma página sobre autismo [...] (E3).

No entanto, durante a observação de algumas consultas, percebeu-se que a maioria dos entrevistados não preenchia a página da caderneta da criança destinada à investigação precoce dos sinais e sintomas do TEA.

Assim, conhecimentos adquiridos tanto nas cartilhas, como na mídia ou em experiências compartilhadas têm contribuído nas intervenções de enfermagem que suscitam sentimentos.

\section{Sentimentos dos profissionais ao acompanharem crianças com TEA}

É comum que o profissional sinta-se confuso, frustrado e incapaz de lidar com a temática, quando alega o pouco conhecimento sobre o assunto.

É frustrante. Senti meio impotente, porque nós estávamos sem saber como lidar [...] (E1).

Me sinto quase que incapaz pela falta realmente de dominio do assunto [...] (E2).

Esse sentimento de incapacidade também é percebido nos registros dos diários de campo, quando a expressão "fora do normal" é utilizada para referir crianças autistas, estando implícito o desconhecimento sobre a temática e a presença do estigma social. Além desse fato, observou-se que alguns enfermeiros, apesar de terem aceitado participar da pesquisa, limitaram-se a responder algumas perguntas, talvez por medo de julgamento ou receio de exposição.

Sentimento de raiva também foi citado, quando a mãe apresentava negação diante dos comportamentos inadequados apresentados pela criança.

No início a mãe negou, isso até me deixou com raiva [...] (E9).

Entretanto, sentimentos de bem-estar e gostar de colaborar também foram citados. Quando conseguiam identificar os sinais e sintomas do TEA e colaboravam com a intervenção, seus sentimentos passavam a ser de satisfação e segurança.

Eu me sinto bem em ajudar aquela criança e a família. Gosto de contribuir com o diagnóstico, para que a criança tenha melhor atendimento e mais qualidade de vida [...] (E9).

Eu sei que quanto mais cedo identificar, melhor. Então, eu iria me sentir bem, me sentir o máximo! A gente fica muito satisfeita quando consegue ajudar as pessoas. (E3).

\section{Discussão}

Pesquisas evidenciaram o quanto é necessário que o enfermeiro intervenha de maneira eficiente junto à própria criança que demanda cuidados exigentes ${ }^{(13-14)}$ e que disponibilize apoio a sua família, por ser o profissional que tem uma relação direta com esse ser ${ }^{(13)}$. Tal compreensão corrobora os resultados desta pesquisa.

Nesse sentindo, a análise dos resultados deste estudo permitiu identificar-se, na atuação do enfermeiro, percepções para a detecção precoce do TEA, como também as intervenções realizadas por esse profissional, suas dificuldades, o modo como construiu o conhecimento sobre essa temática e os seus sentimentos no acompanhamento à criança com indícios desse diagnóstico.

Assim, no que se refere às percepções, estratégias e intervenções do enfermeiro sobre sinais e sintomas, corroborando o referido na literatura, esse profissional considera que a criança com TEA revela intensas modificações no comportamento e na comunicação social, tais como condutas ritualistas, autoagressividade, mudanças no padrão do sono e alimentação, crise de birra, fobia sem especificação, dificuldades para compreender a realidade, estímulos sensoriais alterados, limitações para participar de jogos e brincadeiras coletivas, isolamento social com interações afetuosas em menor intensidade. Entretanto, mantém a capacidade de memorização, o que torna possível avanços cognitivos quando estimulada ${ }^{(6,15)}$.

O diagnóstico feito nos três primeiros anos de vida é essencial para o desenvolvimento de capacidades, inclusive do desenvolvimento escolar, uma vez que abordagens terapêuticas 
precocemente implementadas aumentam as possibilidades de respostas positivas, devido à maior plasticidade de estruturas anátomo-neurofisiológicas do cérebro nesse período ${ }^{(16)}$. Uma revisão integrativa, que retratou as produções científicas sobre os cuidados de enfermagem às crianças com TEA, revelou o quanto é importante o conhecimento do enfermeiro para possibilitar o reconhecimento, o mais precocemente possível, dos primeiros sinais e sintomas desse distúrbio no período de crescimento e desenvolvimento da criança ${ }^{(17)}$.

Entretanto, é comum os profissionais sentirem-se inseguros, despreparados na avaliação dos sinais e sintomas, o que acarreta demora no diagnóstico e compromete a identificação precoce. Isto leva a família e a criança a passarem sucessivamente por vários profissionais e instituições antes que seja constatado o TEA, retardando, desse modo, qualquer tipo de intervenção que contribua para a melhoria do crescimento e desenvolvimento do infante ${ }^{(16)}$. Estudo evidenciou a necessidade de capacitação dos enfermeiros no que se refere ao diagnóstico, tratamento e acompanhamento da criança com TEA, bem como o reconhecimento de suas necessidades ${ }^{(17)}$.

Ressalta-se que, para fornecer subsídios aos profissionais da saúde, principalmente da atenção básica, o Ministério da Saúde tem contribuído, ao publicar manuais com diretrizes e instruções que descrevem os sinais observáveis em cada fase do desenvolvimento infantil e propõe instrumentos facilitadores da avaliação e do acompanhamento do desenvolvimento, que podem ser utilizados durante as consultas, tais como: o Questionário de Desenvolvimento da Comunicação (QDC), o Modified-Checklist for Autism in Toddlers (M-Chat) e os Sinais Preaut ${ }^{(6)}$.

No entanto, nem sempre é possível verificar tais sintomas, se a criança não é conduzida à UBS. E isso ocorre quando a família não percebe os sinais disfuncionais nos primeiros 24 meses de vida, seja por proteção frente aos estigmas sociais, seja por negação ou desinformação, seja, em casos extremos, por negligência com a criança. Desse modo, o enfermeiro, ao realizar a consulta de enfermagem no infante de forma periódica, deve avaliar e acompanhar o crescimento e desenvolvimento das menores de dois anos, a fim de planejar estratégias de atuação de acordo com as necessidades encontradas ${ }^{(1,6,9)}$.

Os sinais apresentados pela criança devem ser avaliados e verificados pelo enfermeiro juntamente com a equipe nos seguintes momentos, para perceber alterações: na Entrevista inicial, com os pais ou responsáveis; na história social, familiar e de saúde da criança; e na avaliação propriamente dita do desenvolvimento e comportamento da criança ${ }^{(6)}$.

Desse modo, o olhar atento do enfermeiro, associado a um raciocínio perspicaz, irá nortear as intervenções de forma resolutiva. Os relatos das mães auxiliam a fundamentar a atuação do profissional no processo. É nesse momento que elas expõem suas ansiedades em relação ao seu filho, possibilitando um canal de comunicação entre serviço e família ${ }^{(3,15-16,18)}$

Intervir na melhoria da qualidade de vida dessa família é função do enfermeiro. A presença de estereótipos e sintomas, como alterações no padrão do sono, agitação, gritos, heteroagressividade, automutilação e falta de reciprocidade social e emocional, leva a família, muitas vezes, a sentir-se impotente, absorvendo um elevado nível de estresse ${ }^{(19)}$.

Uma revisão sistemática com estudos qualitativos, quantiqualitativos e relatos de casos, que retratou os desafios encontrados e estratégias de enfrentamento pelas famílias com crianças com TEA, confirmou os achados deste estudo com relação à postergação do diagnóstico, quanto aos sintomas mais relacionados ao TEA e ao estresse $^{(14)}$.

Além da atenção ao que o familiar revela quanto a si e quanto ao comportamento de sua criança, é necessária, para o arcabouço do conhecimento do profissional, a observação direta da criança, dos seus reflexos e do modo como interage no ambiente. Não só o enfermeiro, mas toda a equipe de saúde precisa estar instrumentalizada para identificar as alterações tanto para o TEA como para qualquer outra doença ou transtorno. É necessária a observação não 
apenas da presença ou ausência de habilidades e/ou capacidades, como também a frequência e a forma como essas ocorrem dentro do contexto de vida ${ }^{(6,17,20-21)}$.

Estudo recente revela que transtornos autísticos podem apresentar-se em diferentes graus de intensidades na criança, indo desde a incapacidade de comunicar-se até uma extraordinária habilidade intelectual. Também aponta um elevado nível de estresse nos educadores e ainda destaca que professores com mais experiência encaram o trabalho com crianças portadoras de TEA como um desafio. Além disso, essa pesquisa ratifica a necessidade de investimentos em promoção à saúde voltados para a escola, e que enfermeiros precisam perceber o ambiente educacional como contexto à continuidade de suas intervenções $^{(15)}$. Isto é, o enfermeiro pode intervir, realizando psicoeducação familiar, aconselhamento para professores, reabilitação na comunidade, apoio aos cuidadores, ações de promoção e proteção dos direitos humanos da criança e de sua família, acompanhamento nos retornos regulares e nos critérios para encaminhamentos a outros serviços ${ }^{(22)}$.

Desde as primeiras suspeitas até o encaminhamento correto, os profissionais encontram muitas dificuldades, tais como a falta de informação e capacitação sobre como proceder e decidir o destino do tratamento. Na prática cotidiana das unidades básicas de saúde, essas dificuldades limitam as ações dos profissionais, que alegam não ser de sua responsabilidade a prestação de cuidados destinados às emoções e aos comportamentos. Assim, a assistência à saúde mental passa a ser ofertada somente por aqueles profissionais que possuem alguma afinidade com a área ou compreendem, mesmo que de forma insipiente, o processo de adoecimento mental $^{(16,23)}$.

Essa cultura de que cuidar das emoções é responsabilidade de profissionais especializados na área mental passa a distanciar ainda mais os profissionais das unidades básicas do atendimento, como de fato deveria ocorrer. Entretanto, é necessário ter em vista o preconizado pelo SUS quanto às ações na ESF, que devem ocorrer de forma preventiva, visando à recuperação e reabilitação das pessoas de forma universal, integral e contínua, mediante uma assistência humanizada, não excluindo pessoas que sofrem transtornos psiquiátricos.

É possível perceber que um dos motivos para tamanho desinteresse dos profissionais na área pode estar relacionado à falta de estímulos durante a formação acadêmica, que, em alguns momentos, carece de conteúdos de saúde mental na grade curricular ${ }^{(10,23)}$. Além disso, a falta de capacitações ofertadas pelos serviços, voltadas para saúde mental, em geral ou especialmente o TEA, também limitam a atuação do profissional. Uma vez que capacitações devem ocorrer, para viabilizar a melhoria das atividades de trabalho, elas podem acontecer de forma permanente no cotidiano do serviço, nas reuniões ricas em discussões de condutas entre os demais profissionais $^{(23)}$.

Outro papel importante que se atribui às capacitações é a informação de como o sistema em rede funciona, quando detectada uma situação de maior complexidade, que precise de atendimento especializado. É necessária interação entre centros de atendimento especializado e equipes atuantes nas ESF, para garantir melhor acompanhamento, possibilitar ações direcionadas às necessidades do usuário e favorecer a continuidade da assistência ${ }^{(6,9,23)}$, como, por exemplo, o matriciamento efetivo entre a Estratégia Saúde da Família e os CAPS.

O enfermeiro, ao prestar cuidados à criança nos diversos serviços, irá buscar fontes para construir seu conhecimento sobre TEA. Em algumas situações, a mídia assume a posição de ponto de partida na busca desses saberes. Rotineiramente é nos meios de comunicação, como em novelas e documentários, que determinado assunto incita a curiosidade e se passa a conhecer um pouco mais sobre tudo o que gira em torno dele, em particular esse transtorno, e pode despertar o interesse pela busca de conhecimento específico em outros meios. Desse modo, a mídia contribui com a formação de conhecimento dos profissionais. Todavia, o contato desse profissional com sinais e sintomas do transtorno na consulta tem 
sido uma das maiores motivações para a busca de informações sobre TEA. A incerteza sobre a temática implica na necessidade de recolher informações e, para isso, a internet é reconhecida como principal fonte de informação, por se tratar de um universo que dispõe de inúmeros conhecimentos de fácil acesso. Entretanto, é necessário o cuidado de recolher informações de fontes seguras e embasadas em conhecimento científico. A convivência com terceiros que têm contato direto com a realidade do TEA, como colegas de trabalho ou familiares, também pode servir de auxílio na edificação do conhecimento sobre o assunto.

Apesar de os profissionais buscarem informações nas mais diversas fontes, muitos ainda não atentaram para as instruções que a própria caderneta da criança traz sobre TEA. Nesta há uma página que contém informações básicas que podem auxiliar o profissional na identificação de um possível caso de autismo. Ela traz alguns sinais do TEA que podem ser associados ao comportamento da criança. É necessário que o enfermeiro conheça bem os instrumentos com os quais trabalha diariamente, para que possa exercer sua função de forma plena e oferecer os cuidados de forma contínua e sem deficiências ${ }^{(6,16)}$.

Entende-se que, diante de situações adversas, é comum que sentimentos de diferentes naturezas, desde frustração pelas dificuldades encontradas até a própria motivação, impulsionem o profissional a ofertar melhor qualidade de vida para a criança e sua família. Além das dificuldades estruturais físicas, da comunidade, e materiais, o enfermeiro sofre ao sentir-se despreparado $^{(23)}$. Ao perceber que seus objetivos não estão sendo alcançados e diante de um transtorno de pouco domínio como o TEA, o enfermeiro sente-se frustrado. Sente-se momentaneamente incapaz de ajudar aquela criança e sua família que sofrem com o TEA. Em alguns casos, quando a família não contribui com o planejamento ou nega-se a aceitar o que está sendo orientado, o enfermeiro pode encarar essa situação como desvalorização de seu trabalho e desenvolver, temporariamente, sentimentos de revolta e raiva.
Por outro lado, sentimentos motivadores, como otimismo e busca por informações sobre o TEA, podem renovar o modo de assistência de enfermagem, garantindo o cuidado continuado preconizado pelo Sistema Único de Saúde.

Os achados na literatura científica convergem com os deste estudo, quando se trata da necessidade de capacitação dos enfermeiros, do retardo no diagnóstico da criança com TEA, dos sinais e sintomas manifestados pelas alterações no comportamento das crianças com tal diagnóstico, do estresse vivenciado pelos familiares e da necessidade de receberem ajuda ${ }^{(13-14,17,24)}$. Este estudo também contribui quando revela os diversos sentimentos experimentados pelos enfermeiros ao acompanharem essas crianças e seus familiares.

Entre os fatores limitantes do estudo, destaca-se o pequeno número de entrevistados, que não se considera representativo do município de Maceió, por se tratar de um fenômeno específico para uma dada amostra, e também o uso de entrevistas semiestruturadas individuais e pontuais, que poderiam ter sido aprofundadas com o recurso de algum instrumento de avaliação validado que verificasse o impacto das ações. Essas limitações mostram a necessidades de pesquisas complementares. No entanto, o resultado deste estudo pode ser considerado uma ferramenta útil para o planejamento de políticas e ações de educação permanente dirigidas aos profissionais da atenção básica, em especial os enfermeiros.

\section{Conclusão}

Este estudo possibilitou a identificação da percepção, estratégias e intervenções do enfermeiro junto à criança com sinais e sintomas de TEA. A atuação nesse cenário exige que esse profissional esteja capacitado para exercer tal detecção de maneira eficaz, já que o tratamento pode ser iniciado quanto mais precocemente o TEA for identificado.

Ressalta-se ainda que a atuação dos enfermeiros na detecção precoce de sinais e sintomas do TEA enfrenta muitas dificuldades, entre elas o pouco conhecimento sobre o assunto, 
a formação acadêmica deficitária e o pouco investimento em educação permanente, além de esses profissionais vivenciarem sentimentos diversos ao se defrontarem com as necessidades da criança e de seus familiares.

Desse modo, a fim de não negligenciar ou responsabilizar outras categorias profissionais por tal intervenção, a preparação do profissional enfermeiro da ESF para intervir junto à criança com TEA torna-se indispensável. A intervenção assertiva do enfermeiro em articular a ESF com uma rede, para que outros serviços possam ser acionados e façam parte de um arranjo terapêutico, é essencial para dar início, o quanto antes, aos cuidados que possibilitem melhor qualidade de vida à criança e sua família.

Nesse contexto, estimular ações de educação permanente nos serviços voltados para sinais, sintomas e intervenções de crianças com TEA é essencial, principalmente aquelas que incentivem mudança de postura e de práticas de enfermagem na ESF. Desse modo, pode-se colaborar com a redução dos estigmas e com ações de promoção à saúde mental que transformem a atuação desses profissionais em relação ao TEA e favoreçam o melhor prognóstico à criança e ajuda aos familiares.

\section{Colaborações:}

1. concepção, projeto, análise e interpretação dos dados: Yanna Cristina Moraes Lira Nascimento, Cintia Soares Cruz de Castro e José Leandro Ramos de Lima;

2. redação do artigo e revisão crítica relevante do conteúdo intelectual: Yanna Cristina Moraes Lira Nascimento, Cintia Soares Cruz de Castro, José Leandro Ramos de Lima e Maria Cicera dos Santos de Albuquerque;

3. aprovação final da versão a ser publicada: Yanna Cristina Moraes Lira Nascimento, Maria Cicera dos Santos de Albuquerque e Daniele Gonçalves Bezerra.

\section{Referências}

1. Zanon RB, Beckes B, Bosa CA. Identificação dos primeiros sintomas do autismo pelos pais. Psic Teor Pesq. 2014 mar;30(1):25-33.

2. American Psychiatric Association. Manual diagnóstico e estatístico de transtornos mentais: DSM-5. 5a ed. Porto Alegre: Artmed; 2014.

3. Elbert M, Lorenzini E, Silva EF. Mães de crianças com transtorno autístico: percepções e trajetórias. Rev Gaúcha Enferm. 2015 mar;36(1):49-55.

4. Ramírez GR. Trastorno del espectro del autismo. Diagnostico. 2014 set;53(3):142-8.

5. Carvalho FA, Paula CS, Teixeira MCTV, Zaqueu LCC, D'Antino MEF. Rastreamento de sinais precoces de transtorno do espectro do autismo em crianças de creches de um município de São Paulo. Psicol Teor Prat. 2013 ago;15(2):144-54.

6. Brasil. Ministério da Saúde. Diretrizes de autismo à reabilitação da pessoa com Transtornos do Espectro do Autismo (TEA). Brasília; 2014.

7. Damasceno SS, Nóbrega VM, Coutinho SED, Reichert APS, Toso BRGO, Collet N. Saúde da criança no Brasil: orientação da rede básica à Atenção Primária à Saúde. Ciênc Saúde Coletiva. 2016;21(9):2961-73.

8. Arantes LJ, Shimizu HE, Hermann EM. Contribuições e desafios da Estratégia Saúde da Família na Atenção Primária à Saúde no Brasil: revisão de literatura. Ciênc Saúde Coletiva. 2016;21(5):1499-509.

9. Andrade RD, Santos JS, Pina JC, Silva MAI, Mello DF. A puericultura como momento de defesa do direito à saúde da criança. Ciênc Cuid Saúde. 2013 dez;12(4):719-27.

10. Nunes SC, Souza TZ, Giunco CT. Autismo: conhecimento da equipe de enfermagem. CuidArte Enferm. 2009 dez;3(2):134-41.

11. Minayo MCS. O desafio do conhecimento: pesquisa qualitativa em saúde. 12a ed. São Paulo: Hucitec; 2010.

12. Bardin L. Análise de conteúdo. Reimpressão. Brasil: Edições 70; 2014. 
13. Nogueira MAA, Rio SCMM. A família com criança autista: apoio de enfermagem. Rev Port Enferm Saúde Mental. 2011 jun;5:16-21.

14. Gomes PTM, Lima LHL, Bueno MKG, Araújo LA, Souza N. Autism in Brazil: a systematic review of family challenges and coping strategies. J Pediatr. 2015;91(2):111-21.

15. Cappe É, Poirier N, Boujut É, Nader-Grosbois N, Dionne C, Boulard A. Autism spectrum disorder and evaluation of perceived stress parents and professionals: Study of the psychometric properties of a French adaptation of the Appraisal of Life Event Scale (ALES-vf). Encephale. 2017 Aug;43(4):321-5.

16. Jendreieck CO. Dificuldades encontradas pelos profissionais da saúde ao realizar diagnóstico precoce de autismo. Psicol Argum. 2014 jun;32(77):153-8.

17. Sousa AMBS, Sousa CS. Produções científicas sobre os cuidados de enfermagem às crianças com Transtorno do Espectro Autista (TEA). Rev Cient Multidisc Núcleo Conhecimento. 2017 abr;2(1):387-406.

18. Gorlin JB, McAlpine CP, Garwick A, Wieling E. Severe childhood autism: the family lived experience. J Pediatr Nurs. 2016 Dec;31(6):580-7.

19. Bonis SA, Sawin KJ. Risks and Protective Factors for Stress Self-Management in Parents of Children
With Autism Spectrum Disorder: An Integrated Review of the Literature. J Pediatr Nurs. 2016 Nov-Dec;31(6):567-79.

20. Souza RS, Ferrari RAP, Santos TFM, Tacla MTGM. Atenção à saúde da criança: prática de enfermeiros da saúde da família. Rev Min Enferm. 2013 jun;17(2):331-9.

21. Reis HIS, Pereira APS, Almeida LS. Características e especificidades da comunicação social na perturbação do Espectro do Autismo. Rev Bras Ed Esp. 2016 set;22(3):325-36.

22. Organização Mundial da Saúde. MI-mhGAP Manual de Intervenção para Transtornos Mentais, Neurológicos e por Uso de Álcool e outras Drogas para os serviços de atenção a saúde não especializados: Programa de Ação para reduzir as lacunas em saúde mental. Genebra; 2015 (Impresso no Brasil)

23. Sena RCF, Reinalde EM, Silva GWS, Sobreira MVS. Práticas e conhecimentos dos enfermeiros sobre o autismo infantil. J Res Fundam Care. 2015 set;7(3):2707-16.

24. Ebert M, Lorenzini E, Silva EF. Mães de crianças com transtorno autístico: percepções e trajetórias. Rev Gaúcha Enferm. 2015 mar;36(1):49-55.

Recebido: 20 de janeiro de 2018

Aprovado: 12 de março de 2018

Publicado: 23 de maio de 2018

A Revista Baiana de Enfermagem utiliza a Licença Creative Commons - Atribuição-NãoComercial 4.0 Internacional.

https://creativecommons.org/licenses/by-nc/4.0/

Este artigo é de acesso aberto distribuído sob os termos da Licença Creative Commons (CC BY-NC).

Esta licença permite que outros remixem, adaptem e criem a partir do seu trabalho para fins não comerciais e, embora, os novos trabalhos tenham de lhe atribuir o devido crédito e não possam ser usados para fins comerciais, os usuários não têm de licenciar esses trabalhos derivados sob os mesmos termos. 